\title{
Discussion on Promotion Model of the TRIZ Theory with the Background of "Mass Entrepreneurship and Innovation"
}

\author{
Xuebo Yan ${ }^{1,3, a}$, Ziqian Zhang ${ }^{2,3, b}$ \\ ${ }^{1}$ Nanjing Vocational Institute of Transport Technology, Nanjing, 211188, China \\ ${ }^{2}$ Information Bureau of the Food Safety Office of the State Council, Beijing, 100053, China \\ ${ }^{3}$ Wonkwang University, Iksan, 54538, Korea \\ ayanxuebo@126.com, bheroziqian@126.com
}

\begin{abstract}
Mass Entrepreneurship and Innovation" has been the development trend of the era with the strong impulsion of the Government of China, which promotes innovation as selfawareness participated by all people. As the foundation of independent innovation, it is important to popularize innovation approach to improve the capability of independent innovation. This article conducts analysis on the current status and investigation results of the TRIZ theory, and designs the TRIZ theory promotion and application system with "dominated by government, with joint participation of multiple subjects". In addition, it proposes the new TRIZ promotion model and related strategies of TRIZ under the new situation, providing references for further promotion of the TRIZ.
\end{abstract}

Keywords-mass entrepreneurship; mass innovation; TRIZ; promotion model

\section{INTRODUCTION}

Since the introduction of the training on TRIZ theory by IWINT. LTD. in 2001, the TRIZ theory has been recognized and promoted in small ranges in China. IWINT. LTD. established related company as well as research and development base in China in 2002. Since then, the TRIZ theory has been increasingly promoted, which has been popularized and promoted in China.

Starting from the strategic attitude of improving the capability of independent innovation and constructing of an innovation-originated nation, the Ministry of Science and Technology decided to vigorously develop the promotion and application of technological innovation in May 2007. In all innovative approaches, the TRIZ theory is mostly noticed by scientific and technical workers and enterprises. As an approach with favorable operability, systematicness and practicability, the TRIZ theory is the main content in innovative approach promotion in our country [1].

The Ministry of Science and Technology issued "Opinions on Strengthening of Innovative Approaches" in 2008 together with 5 other ministries and commissions such as the National Development and Reform Commission and the Ministry of Education in 2008, to start innovative approach related works in 28 provinces, cities and autonomous regions. Multiple stages of special works of innovative approaches have been undertaken and the promotion and application work of the
TRIZ theory has been developed. Since then, the TRIZ theory has been widely promoted in China.

\section{PROMOTION HistORY AND CONDITIONS OF THE TRIZ THEORY IN CHINA}

TRIZ is the Latin characters converted from abbreviation of Russian, with the significance of "theory of Inventive Problem Solving"; it is also provided with a Chinese name of "Cuizhi" theory by a Chinese expert. The TRIZ theory is a whole set of practical theoretical method system established by Altshuler, a former Soviet Union scholar, by arranging, concluding, abstracting and reconstructing of millions of patent documents in more than 50 years [2]. After the promotion and practice of more than half a century the TRIZ theory has been developed to a set of mature theory and method system. Millions of technological inventions have been crated according to the technological innovation approach, TRIZ, which have been widely applied in every corner of the world and have created huge economic benefits and social benefits for a lot of famous enterprises.

The TRIZ theory is a set of systematic and practical theoretical system solving problems involved in invention creation by a group of scholars led by Genrich Altshuler, an inventor of the former Soviet Union according to more than 2.5 million patent documents in the world with dozens of years since 1946. Based on the inherent objective law of the evolution of technological system, it conducts logical analysis and scheme combination to problems. It guides people to innovate step by step but not in a blind or arbitrary way. It provides a series of tools, including 40 principles and contradiction matrixes solving technological contradictions, 4 separation principles solving physical contradicts, 76 standard solving methods and algorithms for invention problems (ARIZ) as well as tools and resources for eliminating psychological contradictions, i.e., time and cost operator, to make people operate and execute different problems in different stages and time as per different solving methods [3-4]. Therefore it is available to quantize and control the invention, but not inventing only based on inspiration and comprehension. The occurrence of the TRIZ theory, the theory of Inventive Problem Solving, provides people with a new set of innovation theory and methodology, opening the new era of inventions and innovations. 
TABLE I. MILESTONE EVENTS OF THE TRIZ THEORY IN THE PROMOTION IN CHINA

\begin{tabular}{|c|c|}
\hline Time & Events \\
\hline 2001 & $\begin{array}{l}\text { After the introduction of the TRIZ theory in China by IWINT. LTD., the TRIZ theory has been } \\
\text { gradually recognized and promoted in small ranges in China. }\end{array}$ \\
\hline 2002 & IWINT. LTD. established the company and research and development base in China. \\
\hline 2003 & $\begin{array}{l}\text { IWINT. LTD. pushed out the training software of the TRIZ theory as well as CBT/NOVA and as } \\
\text { set of training system. }\end{array}$ \\
\hline 2004 & $\begin{array}{l}\text { IWINT. LTD. cooperated with the international TRIZ association to introduce TRIZ } \\
\text { international certification into China. }\end{array}$ \\
\hline 2005 & $\begin{array}{l}\text { IWINT. LTD. introduced and organized to translate the latest edition of the TRIZ teaching } \\
\text { material, "How to Become an Inventor - Creation within } 50 \text { Hours". }\end{array}$ \\
\hline 2006 & $\begin{array}{l}\text { IWINT. LTD. established the TRIZ training teaching material and the training software } \\
\text { according to the China's national conditions. }\end{array}$ \\
\hline May 2007 & $\begin{array}{l}\text { The Ministry of Science and Technology held the "Seminar on Training of Enterprise } \\
\text { Technology Innovations", with more than } 50 \text { participants from test units in Zhejiang, Jiangsu, } \\
\text { Shaanxi, Sichuan and Heilongjiang. }\end{array}$ \\
\hline June 2007 & $\begin{array}{l}\text { Three academicians including Wang Daheng, Liu Dongsheng and Ye Duzheng wrote to Prime } \\
\text { minister Wen Jiabao, to suggest to strengthen the works related to innovative approaches in our } \\
\text { country. }\end{array}$ \\
\hline July 2007 & $\begin{array}{l}\text { According to the instructions from Prime minister Wen Jiabao, "the three senior scientists } \\
\text { propose to "innovate the method for independent innovation". The innovation on approach is the } \\
\text { foundation for independent innovation. This is an important opinion, in need of high attention. The } \\
\text { three suggestions shall be conducted with in-depth research by the Ministry of Science and } \\
\text { Technology, the Ministry of Education and the National Development and Reform Commission in } \\
\text { combination with practical conditions." }\end{array}$ \\
\hline August 2007 & $\begin{array}{l}\text { According to the formally reply from the Ministry of Science and Technology, Sichuan Province } \\
\text { was taken as the experimental province for the technological innovation method. }\end{array}$ \\
\hline October 2007 & $\begin{array}{l}\text { The Ministry of Science and Technology, National Development and Reform Commission, the } \\
\text { Ministry of Education and China Association for Science and Technology reported the working } \\
\text { thoughts and detailed developed works about the innovation of the method. }\end{array}$ \\
\hline $\begin{array}{l}\text { November } \\
2007\end{array}$ & $\begin{array}{l}\text { Prime minister Wen Jiabao reviewed "the report on vigorous promotion of innovation method" } \\
\text { and instructed as "agree". }\end{array}$ \\
\hline April 2008 & $\begin{array}{l}\text { The Ministry of Science and Technology, the Minister of Education, the National Development } \\
\text { and Reform Commission and China Association for Science and Technology jointly issued the } \\
\text { "Opinions on Strengthening of Innovation Methods". }\end{array}$ \\
\hline 2008 & $\begin{array}{l}\text { The Ministry of Science and Technology issued "Opinions on Strengthening of Innovative } \\
\text { Approaches" together with } 5 \text { other ministries and commissions such as the National Development } \\
\text { and Reform Commission and the Ministry of Education, to start the innovation of the methods } \\
\text { related works in } 28 \text { provinces, cities and autonomous regions. }\end{array}$ \\
\hline April 2008 & $\begin{array}{l}\text { The seminar on training experimental units for national technological innovation methods was } \\
\text { held in Harbin. More than } 50 \text { experts from Policy and Regulatory Reform Division of the Ministry of } \\
\text { Science and Technology, China's Agenda } 21 \text { Management Center and Department of Science and } \\
\text { Technology of Heilongjiang participated in the seminar. }\end{array}$ \\
\hline October 2009 & $\begin{array}{l}\text { "High-rise Forum on Innovation of Method of 2009" was held in Beijing. The forum was } \\
\text { conducted with the theme of "promoting economic growth by promoting innovative methods and } \\
\text { self-independent innovation". It aimed to implement the "strengthening method innovation related } \\
\text { works to promote the construction of the innovative country" proposed in "Opinions on } \\
\text { Strengthening of Innovative Approaches", to vigorously promote independent innovations. }\end{array}$ \\
\hline 2009 & $\begin{array}{l}\text { According to the reply of the Ministry of Science and Technology, Guangdong, Tianjin, } \\
\text { Zhejiang, Shandong, Hubei, Chongqing, Shaanxi, Xinjiang and Xiamen became the second batch of } \\
\text { experimental provinces and cities for method innovation. }\end{array}$ \\
\hline $\begin{array}{l}\text { December } \\
2010\end{array}$ & $\begin{array}{l}\text { The "high-rise forum on method innovation of } 2010 \text { " was held in Beijing. The high-rise forum } \\
\text { took "method, innovation and changes" as the theme, to discuss on how to improve independent } \\
\text { ability through research and application of method innovation, as well as how to accelerate the } \\
\text { change on economic development method through method innovation. }\end{array}$ \\
\hline January 2013 & $\begin{array}{l}\text { Totally } 27 \text { provinces, cities and autonomous regions became experimental units for the method } \\
\text { innovation. }\end{array}$ \\
\hline
\end{tabular}


Up until 2015, there had been totally 28 regional innovation bases and 4 national innovation bases in the whole country. It had been widely promoted in 28 provinces, cities and autonomous regions with related promotion and application bases. Totally 40 thousand high-end innovation talents had been cultivated and 719 experimental and demonstrated enterprises of various levels had been constructed. According to incomplete statistics, the method innovation assisted enterprises to apply for 7672patients during 2008-2014, including 2584 patent for invention.

In order to figure out the benefits generated and the popularization condition of the TRIZ theory since the introduction of the TRIZ theory into China for more than ten years, the author conducts investigation to the entrepreneurs and the office workers in Mass Entrepreneurship and Innovation in Jiangsu, Hubei, Henan and Zhejiang in a random way. The investigation was conducted with the unit of person, and the entrepreneurs and the office workers with educational history of at least junior colleges are adopted as the objectives, and totally 378 questionnaires are collected within three months. The investigation and statistics on the recognition on the TRIZ theory are shown in the following table.

TABLE II. SURVEY OF SOCIAL COGNITIVE STATUS OF TRIZ THEORY

\begin{tabular}{|l|c|c|}
\hline \multicolumn{1}{|c|}{ Investigated problem } & $\begin{array}{c}\text { Number of } \\
\text { people }\end{array}$ & Proportion \\
\hline $\begin{array}{l}\text { Have no idea and have never } \\
\text { heard of that }\end{array}$ & 178 & $47.1 \%$ \\
\hline Slightly understand it & 79 & $20.9 \%$ \\
\hline $\begin{array}{l}\text { Have some methods but have } \\
\text { not applied to practice }\end{array}$ & 87 & $23.2 \%$ \\
\hline $\begin{array}{l}\text { Have in-depth learning and } \\
\text { have applied to practice }\end{array}$ & 34 & $9.0 \%$ \\
\hline
\end{tabular}

Based on the above statistics, the TRIZ theory fails to have a sufficient popularity degree, and the number of people applying the TRIZ theory is only $9 \%$ of all the respondents. The respondents who "Have no idea and have never heard of that" occupy $47.1 \%$ of all the respondents, and nearly a half of the respondents do not heard of that at all. Therefore, it is needed to promote the TRIZ theory in an in-depth way [5-6].

The TRIZ theory has been promoted in ways of trainings in recent years, including two main aspects: the trainings aiming at teachers and students, with main contents of learning the theory and method of the TRIZ theory, supplemented with related practical trainings; the training aiming at engineering technology research and development personnel in enterprises, with main contents of solving practical problems in research and development of enterprises with the guidance of the theory. The core of the TRIZ theory trainings is to cultivate the innovative thoughts of the learners. As a thought weapon and "methodology", it is not only applicable in engineering technology fields but with certain universality. For example, Fudan University plans to introduce the TRIZ theory into the cultivation of artistic talents. Peking University applies it to innovation on management. With very extensive applications, it is still at the stage of experimental units in practical promotion.

\section{OPPORTUNITIES BROUGHT BY "MASS \\ ENTREPRENEURSHIP AND INNOVATION” FOR THE PROMOTION OF TRIZ}

In 2014, global economy was caught in depressed conditions, and there were more and more descending pressure for the economic growth of China. The government-dominated "Mass Entrepreneurship and Innovation" strategy became the new power for economic development in China. Governments in China strongly supported entrepreneurship and innovation, which activated energy for entrepreneurship and innovation and formed the macro-environment of entrepreneurship and innovation, to help entrepreneurs overcome difficulties during entrepreneurial process, so as to research and development new technologies and manufacture new products to form new economic growth points. In this environment, a large number of small and medium-sized enterprises have emerged in China, and a large number of global leading business models and innovative products have been born. At the same time, in order to active market vitality, the implementation of the Mass Entrepreneurship and Innovation gives rise to the enthusiasm of the mass. In real life, innovative business models, products and services are emerging in various industries, and innovation is not the patent of researchers and high technicians. In addition, a national movement includes innovations everywhere, and governments are promoting the cultivation of innovative talents by utilizing various means.

With large amount and wide ranges, middle and small-sized enterprises are the key point as well as the difficult point for structural transformation of the economy in China. Technological innovative ability of middle and small-sized enterprises is related to the technological innovative ability of the whole country. During this process, it is necessary to face to all challenges and support the innovative development of middle and small-sized enterprises. At the same time, middle and small-sized enterprises shall try their best to realize transformation and upgrading through innovations on technology, management and business model.

Method innovation is the generic terms of scientific thought, scientific method and scientific tools. The strengthening of the research and application of method innovation is the important measure to strengthen the capability of independent emotion from the source. In recent years, our country has paid high attention to the innovation development of middle and smallsized enterprises. Enterprises are subjects of technological innovation. According to practice, the technological innovative ability and international competence of the whole country can be upgraded only with the upgrading of wide middle and smallsized enterprises.

At present, the trainings with the main body of enterprises are developed in large scale enterprises and the research and development departments, and it is difficult to pay equal attention to middle and small sized enterprises in short term. The talent cultivation with the carrier of schools cannot be radiated to large numbers of entrepreneurs and in-service staffs. The training of TRIZ is mainly conducted in large-scale research and development enterprises and scientific research institutions, with very expensive training expense, which greatly influence the popularization of the TRIZ theory in 
middle and small-sized enterprises. Therefore, it is difficult for the current promotion model of the TRIZ theory to adapt to the need of "Mass Entrepreneurship and Innovation", and a new promotion model is urgently needed.

\section{THE TRIZ PROMOTION MODEL UNDER THE "MASS ENTREPRENEURSHIP AND INNOVATION" SITUATION}

In consideration of wide distribution of in-service staffs and complicated personnel structure, it is very difficult to organize and implement the training and promotion of the TRIZ theory. Aiming at the new situation of "Mass Entrepreneurship and Innovation" at present, each one has potential innovation ability, which can be motivated through education and training. That is to say, the innovative education can provide the learners with powerful innovative ability. It is available for learners to master the creation theory and method through training, to improve the success rate and level of innovation under the guidance of scientific methodology. In order to adapt to the demand of "Mass Entrepreneurship and Innovation", in combination of the practical situation of time development and the "Internet+ education" model, a new promotion model, the OTC-L model, is proposed by the author. At the same time, the OTC-L model is also a knowledge promotion model, in which $\mathrm{O}$ represents for Organization; $\mathrm{T}$ represents for Teachers; $\mathrm{C}$ represents for Curriculum; L represents for Learners; in which the connotation of $\mathrm{O}$ (Organization) shall be further stipulated in practice. Generally, it mainly includes but not limited to enterprises; it can be any organization suitable and competent for TRIZ talent cultivation and promotion such as scientific research institutions, schools and mass organizations. The new model is applicable to the promotion and application of the TRIZ theory in current environment.

As shown in Figure 1, it takes Learners as the center, and integrates Organization, Teachers and Curriculum, to construct a Trinitarian OTC-L talent cultivation model, and the country organizes related ministries and commissions or provinces to establish the TRIZ resource learning platform for all learners in need of training and learning. In addition, the TRIZ expert library is established to provide learners with on-line guidance and FAQs. The teachers of the expert library can also be employed by relation organizations (such as enterprises, schools and research institutions) to conduct off-line targeted training and guidance. Besides, some excellent institutions can participate in the TRIZ curriculum development and the teacher recommendation works, so as to perfect the on-line curriculum and enrich the teacher teams. It helps form the mutual dependency and common development state.

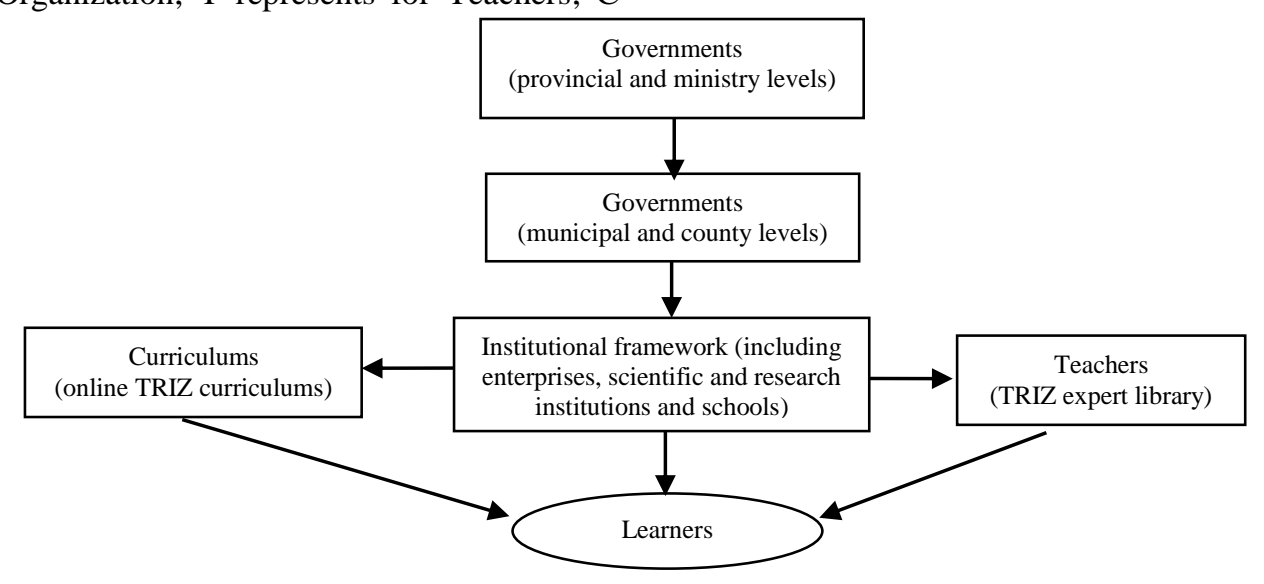

Fig. 1. OTC-L Talent Cultivation Model

In this way, the learner-centered OTC-L promotion model can provide wider range of personnel with TRIZ curriculum, which is beneficial to the large range promotion of the TRIZ curriculum. The participation of institutional frameworks including enterprises, schools and social organizations can make up with the insufficiency of online curriculum, providing learners with individual and targeted guidance and training, to give full play to the TRIZ theory in production practice and generate values.

The combination between entrepreneurial activities and the TRIZ theory will greatly expand the space for innovation. Entrepreneurial activities are innovation activities in essence. A lot of entrepreneurs start from an innovative idea or a new technological invention. The TRIZ theory is engaged in the laws for inventions and innovations, which provides entrepreneurs with new thinking weapons; entrepreneurial activities verify the TRIZ theory in practice, changing the theoretical knowledge into practical productivity.

\section{SUGGESTIONS ON DEVELOPMENT OF THE OTC-L PROMOTION MODEL}

The OTC-L model is a popular and universal promotion model, which can meet the demands on enhancing competitiveness of middle and small-sized enterprises under the "Mass Entrepreneurship and Innovation" situation. In combination of the development of current Internet technology, it is more practical to promote the TRIZ theory with the OTC$\mathrm{L}$ model. In order to ensure the promotion effect and quality, the following measures and suggestions are proposed:

(1) Give full play to the advantages of "Internet+ education" and strengthen the construction of the TRIZ online curriculum platform. At present, related websites on method innovation and learning promotion have been established in Heilongjiang Province, international TRIZ association and Guangdong Province, to provide learners with trainings and 
technical consultations on various innovation theories through network service platform. But based on the browsing amount of the network service platforms, the TRIZ related works are still in primary stages, and no complete TRIZ curriculum system has been constructed. In addition, there is no comprehensive case for practical utilization of TRIZ with only examples of the innovative improvement on certain technology. Besides, the examples of combined innovation between TRIZ and other technologies are only professional descriptions, which are difficult for the public to understand and learn. It is urgent to construct one or several TRIZ online learning platform in the whole country, and construct the curriculum system by taking the theory of MOOC, so as to strengthen the construction of the contents and functions of the website as well as develop the APP software related to learning of the TRIZ theory.

(2) Strengthen the development and promotion of TRIZ theory based computer-assisted innovative design software and tools, so as to develop professional innovation tools in combination of the characteristics of innovation under the "Mass Entrepreneurship and Innovation" environment as well as technical characteristics and innovative demands on industry era development. With the development of dozens of years, the whole TRIZ theory includes huge theoretical system and knowledge system, including a lot of methods for innovative thoughts, rules for technical system evolution, resource analysis, 40 invention principles and contradictions and solutions, field-object model analysis method, standard solutions for invention problems and solving algorithms for invention problems. It is not necessary for ordinary applicators to master all of them, and it is more important to apply related methods to detailed work and practice, so as to promote and design suitable models for enterprise innovation according to promotion experience of TRIZ theory and characteristics of various key industries, to construct the enterprise innovation management method based on the TRIZ theory. It is necessary to construct the TRIZ theory based enterprise innovation management method and conduct innovation, supplementation and perfection on the TRIZ theoretical method system as well as develop matched TRIZ tools and software, so as to further enrich the innovation theory method system. In addition, it is necessary to strengthen the research and development of the innovation platforms and computer-assisted innovative design tools, contradictory issue problem solving and product evolution prediction tools as well as simplify the utilization of the innovation theory of learners, so as to provide them with tool learning instead of theory and method learning, to provide reference and method support for promotion of the TRIZ theory method for various enterprises.

(3) It is necessary for local governments on municipal and county levels to establish guidance capital and make full use of the resources on TRIZ online learning platforms and the expert library and cooperate with organizations such as enterprise and public institutions and schools of corresponding regions to strengthen the promotion and application of the TRIZ theory. local governments shall provide related enterprise and public institutions with financial support to encourage them to promote and guide the in-service personnel and school students to actively participate in TRIZ online curriculum leaning and shall assist learners to participate in TRIZ related certifications or provide related learning certificates in order to encourage enterprises to provide personnel with convenience and subsidization for TRIZ theory. For example, governments shall encourage related enterprises to organize related forums and meetings of exchange on application experience, and support and award on time and finance shall be provided for personnel who participate in related TRIZ training; in this way, governments guide enterprises to pay attention to the combination of the TRIZ theory and practical use. Schools can also adopt TRIZ theory as public elective course and grade the online academic records.

(4) It is needed to promote the diversified promotion method by utilizing the new media and the mobile Internet technology. Compared with the traditional promotion media, the new type media is totally different on method, approach, scale and characters as well as the promotion method. In which the largest difference is on the separation between contents and carrier; the same contents can be delivered to users with different forms through different media and channels. It is necessary to make full use of new media and mobile internet to realize diversified promotion method. In addition, it is needed to create new channels on mobile clients, to introduce TRIZ curriculums to platforms including WeChat and other network curriculum platforms such as Taobao Education, Baidu Classroom, Tencent Classroom and Netease Cloud Classroom, to provide convenience for learners.

\section{CONCLUSION}

“Mass Entrepreneurship and Innovation" encourages all people to conduct innovation and entrepreneurship, which is the social trend in the future. It also promotes the demand and enthusiasm of the society to innovations, and it is necessary to adjust the TRIZ innovation method according to the era background of "Mass Entrepreneurship and Innovation", to conduct reform and innovation, so as to cultivate more talents and contribute to social progresses and economic development.

\section{REFERENCES}

[1] Sun Xiaoou. Research on the Application Model of the TR12 Theory in Enterprise Technology Innovation Engineering of Heilongjiang Province [D] . Jilin University, 2005.

[2] Lu Wei. Anhui-based Research on Service System of Promotion and Application of Technological Innovation Method [D] . Hefei University of Technology, 2012.

[3] Wang Li. Research on Promotion Current Status of the TRIZ Theory in Central Plains Economic Zone, Creative Technology [J]. 2013 (06).

[4] Zhang Guohui and Yu Hao. Research on Promotion Model of the TRIZ Method in Beijing [J] . 2012 (12).

[5] Tan Runhua and Zhang Huangao Interactive Training Model of TRIZ for Mechanical Engineers in China, Chinese Journal of Mechanical Engineering[J] 2014(02).

[6] Li Yuyan; Guo Kai; Zhang Xiangmin .Research on the Application of STC Operator Method in TRIZ Innovation Theory. 1st International Conference on Management, Education and Social Science (ICMESS 2017) [C]2017(06). 